\title{
Embodying Meaningful Digital Media
}

\author{
A Strategy to Design for Product Attachment in the Digital Age
}

\author{
Daniel Orth 1 , Clementine Thurgood ${ }^{2}$, Elise van den Hoven ${ }^{1,3,4,5}$ \\ ${ }^{1}$ Faculty of Engineering and Information Technology, University of Technology Sydney, Sydney, Australia \\ ${ }^{2}$ Faculty of Health, Arts and Design, Swinburne University of Technology, Melbourne, Australia \\ ${ }^{3}$ Department of Industrial Design, Eindhoven University of Technology, Eindhoven, the Netherlands \\ ${ }^{4}$ Duncan of Jordanstone College of Art and Design, University of Dundee, Dundee, Scotland \\ ${ }^{5}$ ARC Centre of Excellence on Cognition and its Disorders, Macquarie University, Sydney, Australia \\ daniel.orth@uts.edu.au, c.thurgood@swin.edu.au, elise.vandenhoven@uts.edu.au
}

\begin{abstract}
Technological products have become central to the ways in which many people communicate with others, conduct business and spend their leisure time. Despite their prevalence and significance in people's lives, these devices are often perceived to be highly replaceable. From a sustainability perspective, there is value in creating technological products with meaning directly associated with their materiality to reduce the rate of product consumption. We set out to explore the potential for design to promote the formation of product attachment by creating technological devices with meaningful materiality, closely integrating the physical form with the significance of its digital contents. We used the life stories and ongoing input of our intended user as inspiration for the creation of Melo, a bespoke music player. The evaluation and critical reflection of our design process and resulting artefact are used to propose a design strategy for promoting product attachment within the growing sector of technological devices.
\end{abstract}

\section{CCS CONCEPTS}

- Human-centered computing User centered design

- Human-centered computing Empirical studies in interaction design $\cdot$ Human-centered computing $\sim$ User studies

\section{KEYWORDS}

Attachment; Digital Media; Materiality; Product Design; SelfIdentity

Permission to make digital or hard copies of part or all of this work for personal or classroom use is granted without fee provided that copies are not made or distributed for profit or commercial advantage and that copies bear this notice and the full citation on the first page. Copyrights for components of this work owned by others than ACM must be honored. Abstracting with credit is permitted. To copy otherwise, or republish, to post on servers or to redistribute to lists, requires prior specific permission and/or a fee. Request permissions from Permissions@acm.org.

TEI'20, February 9-12, 2020, Sydney, NSW, Australia

(C) 2020 Association for Computing Machinery.

ACM ISBN 978-1-4503-6107-1/20/02 .\$15.00

https://doi.org/10.1145/3374920.3374921

\section{ACM Reference format:}

Daniel Orth, Clementine Thurgood and Elise van den Hoven. 2020. Embodying Meaningful Digital Media: A Strategy to Design for Product Attachment in the Digital Age. In Fourteenth International Conference on Tangible, Embedded, and Embodied Interaction (TEI'20), February 9-12, 2020, Sydney, NSW, Australia. ACM, New York, NY, USA. 12 pages. https://doi.org/10.1145/3374920.3374921

\section{INTRODUCTION}

As more aspects of our lives move towards the digital realm, the field of product design is becoming increasingly integrated with interaction design [61]. This transition affects the ways in which we engage with products, including the development of emotional connections with our belongings. It has led researchers working at the intersection of product and interaction design to examine the personal relationships people develop with their technological devices, including the digital information stored or accessed from within. In many cases this work is done in a similar light to those looking at meaningful nondigital objects, with several directly comparing the influence of the physical or digital form on the formation of emotional significance $[2,29,48,55]$. The findings of these studies suggest that people do not value their technological possessions as highly as their non-digital possessions $[29,48,51,55]$. The role of object form on the development of product attachment to a possession has since become a key area of exploration in Human Computer Interaction (HCI) research [6, 23, 28, 29, 34, 49, 60].

The growing presence of digital components within products brings new challenges to designers seeking to promote attachment [34]. Despite their prevalence and significance in people's lives, technological devices such as smartphones, laptops, tablets, e-book readers, game consoles, external hard drives and digital cameras are often perceived to be highly replaceable [29, 32, 48, 53]. Distinctions are often made between the meaning of the 
material device and the digital information it stores or enables. The transferable and evolving nature of personal digital media can distance its significance from association with any single device. Many researchers have explored ways to more closely integrate the physical and digital components of a technological product [24, 30, 33, 34, 62, 67]. While this is often done with the intention of improving the usability of the system, closer integration of physical and digital components may also promote product attachment by ensuring the meaning assigned to a possession is associated with its specific materiality, and not just its digital functionality. We explore the potential for designers to create technological devices with meaningful materiality, closely integrating the physical object with the significance of digital contents.

This article outlines our process of applying product attachment theory to the design of Melo, an interactive music player inspired by a series of interviews conducted with an individual who discussed details of their life story and relationship with their digital music library. We evaluate and reflect on our design process to discuss the effectiveness of our approach and the resulting product in promoting the formation of meaningful associations to the materiality of technological products. We conclude by exploring the applicability and limitations of our findings for promoting product attachment in the growing sector of technological devices.

\section{RELATED WORK}

Through our engagement with the world in which we live, we as humans develop meaningful relationships with things external to ourselves. This phenomenon is characterised by the construct of attachment, defined as an emotional-laden bond connecting an individual with a specific target [9]. Product attachment in particular has been the focus of literature in the fields of psychology, sociology, material culture, consumer behaviour and design $[5,19,44,54]$. There is general agreement that people develop an attachment to a belonging for its role in the construction, maintenance or development of an aspect of their self-identity $[4,5,19,57]$. Meaningful products are used to characterise and communicate who we were, who we are and who we wish to become [57]. Much like material possessions, digital possessions such as photos, songs, emails and apps can be highly valued for their role in selfextension processes [6]. They similarly allow us to express individuality [12], reflect our social ties [39], connect us to our past [34] and remind us of loved ones [66].
People are increasingly acquiring vast collections of personal digital media. These digital collections serve enriching purposes such as exhibiting and reflecting on lived experiences [50], symbolising achievements [38] and connecting with others through reciprocal sharing [7]. While an increase in engagements with digital collections is often seen to reflect the dematerialisation of our consumption behaviours, our contact with digital collections remains deeply rooted in engagements with material artefacts. Magaudda [37] illustrates that alongside the increasing adoption of digital music formats such as the mp3, a vast number of new music listening devices and objects were developed including mp3 players, headphones, mobile phones, portable speakers, docking stations and accessories such as connectors for car sound systems and armbands for listening to music whilst exercising. Studies evaluating existing user-product relationships have found people often do not develop lasting emotional ties with these technological possessions [29, 32, 48]. The existing situation has been described in dire terms as a "disposable technology paradigm" [32, p. 323] in which people are throwing away and replacing technological devices at a rapid rate, intensifying sustainability issues such as resource scarcity and e-waste management [20]. Early work investigating people's attachment to their mobile phones suggested it was not the device itself but rather the relationships with others it embodied that gave it meaning [64]. More recent work looking at mobile phones argue that attachment to the device and the brand or software system overlap and therefore result in attachment that may be transferred to a newer version of the same device [41].

While technological products contain functionality that continues to expand the capabilities of their users, they also signify a shift in human-object relationships. Philosophical critique of technological products argue that the concealment of a device's functionality leads to a diminished sense of worth for the device itself [8, 63]. This concealment of functionality causes a conceptual distinction in the mind of the user between the device and its digital output, for example, an mp3 player and the music it produces or a camera and the digital photos captured. A number of studies have since found distinctions between people's attachment to a thing versus attachment to what it provides [29, 34, 48]. Their findings suggest that people often express strong attachment to what a technological product provides, but rarely to the device itself, instead perceiving them to be highly useful but replaceable tools. Kirk and Sellen [34] found that VHS or cassette tapes held no sentimental value as physical objects yet their contents 
were considered highly significant. The nature of attachment experiences between individuals and their possessions has been scrutinised to better understand the outcomes that result from this emotional bond. Conceptual boundaries have been established between attachment to a specific thing versus a product category [17], brand [25] or possessions in general [5]. From a sustainability perspective, promoting attachment that is specifically assigned to the singular physical device itself has been considered as a viable strategy to address issues with the rate of product consumption $[28,32]$.

Digital photos captured during an overseas holiday can evoke vivid memories of the trip, yet the devices used to capture and store these photos often lack the aesthetic and sensory cues required to bring the same thoughts to mind. There is a need to create long lasting technological products that develop unique personal meanings imbued within their materiality. For this reason, we focus our attention on exploring ways in which designers can create more meaningful and singular technological products by reducing the divide between physical and digital meanings. Several projects have adopted creative methods of materialising digital media, such as Brooklyn-based design studio REIFY's use of audio data from songs to create abstract 3D-printed sculptures or Trace-Marker [35], a system for engraving visualisations of cyclists' journey data onto bags. While these examples are effective in bridging the gap between physical and digital properties, they do not attempt to distinguish between significant and insignificant properties of the digital media or the mental model of the individual user to direct the development of meaningful material forms. To materialise the meaning assigned to digital media, we argue in favour of designing devices to embody the personal, rather than generic, qualities of the media. Manipulating the material properties of an object to evoke personal mental concepts [see 52] provides an alternate means for designers to create shared meaning across the physical and digital components of technological products. In this article, we explore the ways in which technological devices can acquire meaning by embodying the significance of their digital contents.

\section{METHOD}

We adopted a research through design [26] approach to explore the application of product attachment theory to design practices that integrate physical and digital forms. We designed, created and evaluated a bespoke music player, Melo containing four different artefacts that are used to select different categories of songs for playback from within a personal digital music library. In our approach, we saw merit in using in-depth research methods to explore the potential of creating technological products with meaningful materiality for their users. We take an initial look at the potential for design practices to promote product attachment in the growing sector of technological devices. In this section, we introduce the adopted system for embodying meaningful digital media and provide an overview of the procedure we developed for the three phases of our design process. Each of the three phases involved in our process is then described in greater detail together with the resulting findings in the subsequent section.

\section{Idea Development}

We set out to explore the potential value of embodying meaningful digital media as a means of promoting product attachment to technological devices. In doing so, we considered a number of common media categories (e.g. digital collections of photos, music, e-books, videos or working files) and associated devices (e.g. digital photo frames, music players, e-book readers, media players, portable hard drives) to serve as the focus of our explorative process. We eventually settled on designing a music player that attempts to materialise the meanings assigned to a user's collection of digital music. For many years personal music collections have played an important role in peoples identity formation processes by supporting self-reflection [21, 31] and reinforcing membership within different groups $[11,65]$. The recent dematerialisation of music collections in which vinyl, cassettes and CDs are replaced with digital formats of music has been found to reduce their emotional value $[40,59]$ and limit their ability to be used for self-presentation purposes $[11,58]$. The lack of visual and tactile aspects within digital music collections provides a rich opportunity for creating a material device that extends the sensory properties and presence of the music collection within day-to-day life.

As a means of creating a music player that embodies a user's meaningful collection of digital music, we adopt the idea of radio-frequency identification (RFID) tagging physical objects to link them with digital information, creating a tangible interface in which these objects are used to engage with linked digital files. This type of system has been applied in a number of research projects including the Chameleon Table [62], Memodules [42] and the Souvenirs System [47] that each explore linking existing physical souvenirs with digital photo albums to facilitate memory recollection and sharing practices. Similar projects have explored the merit of re-materialising digital music such as 
the Tangible Music Player [3] that uses marbles to represent songs and enable multi-user interactions and Tangible Jukebox [27] that uses paper cards to represent playlists and operate controls on a multi-touch surface. We diverge from these projects by giving greater attention to the materiality and significance of the physical objects themselves and their role as embodiments of the digital media they enable. The system allows music to be linked to a particular object and played by placing the object onto a central platform. This simple method of interaction allows for rich design explorations that focus on the forms, materials and processes used to create each object.

\section{Participant}

We adopted a participatory approach, working with our participant over a six-month period to create a bespoke music player with artefacts inspired by the memories, experiences, emotions and values evoked by their digital music library. As our goal was to create a product that could embody the personal significance of digital media, we sought a participant who had a deep connection and active engagement with their digital music library. We were fortunate to recruit Andrew, a 54-year-old male with a lifelong appreciation for music. Previous studies have highlighted that the experience of attachment is unique to the individual $[45,52]$ and that it is not possible for one design to have emotional value for all intended users [22]. These factors led us to focus our attention on designing for a single user through a three-phase process.

\section{Phase I: Inspiration}

Our intention of creating a bespoke music player that embodies personal meanings for its intended user demanded an empathic approach throughout the design process. To provide guidance to our design process, we conducted a series of in-depth semi-structured interviews with Andrew. Each interview contained a focal theme for questioning with subsequent interviews building upon the insights generated in prior discussions.

\section{Interview I: Identity Narrative}

The first interview was carried out in a café near Andrew's workplace and lasted 1.5 hours. In this interview, we sought to reveal details of Andrew's identity narrative and individuality through discussion of his life story [36], much like the work of Ahuvia [1], which investigated the life history and loved possessions of ten individuals. Interview questioning began by asking Andrew to share details of his life narrative from his childhood to current lifestyle to his aspirations for the future. We then asked Andrew to share stories of his ongoing relationship with music. This included developments in his relationship with music over time, memorable listening experiences and the role of music in relation to various aspects of his life.

\section{Interview 2: Musical Experiences}

The second interview, conducted two weeks later, was carried out in Andrew's home and lasted 2 hours. In this interview, we transitioned to more directly explore Andrew's relationship with his digital music library. We began by inquiring about general associations and experiences related to his day-to-day engagements with his digital music library. To actively involve Andrew in the design process of the music embodiments, we conducted a series of probing activities within the interview to provide us with inspirational insights into his relationship with his digital music library. This began with a process of forming categories of music from within his digital library based on their relationship to different aspects of his self-identity. We then collaboratively identified specific songs, artists, albums or genres that fit within each personal category.

We devised two types of cards (see Figure 1) to inquire about the thoughts evoked by each identified category of music. The first of these cards we refer to as Music Associations cards that asked our participant to list all associations that come to mind when engaging with a music category including memories, experiences, time periods, events, places, people, things, emotions, values, activities, personality traits or qualities. The second of these cards, we refer to as Music Properties cards that involve rating the properties of a music category along twelve bipolar scales related to various sensory concepts such as complexity, form, intensity, texture and weight. We asked Andrew to complete a Music Associations and Music Properties card for each of the prior developed categories of

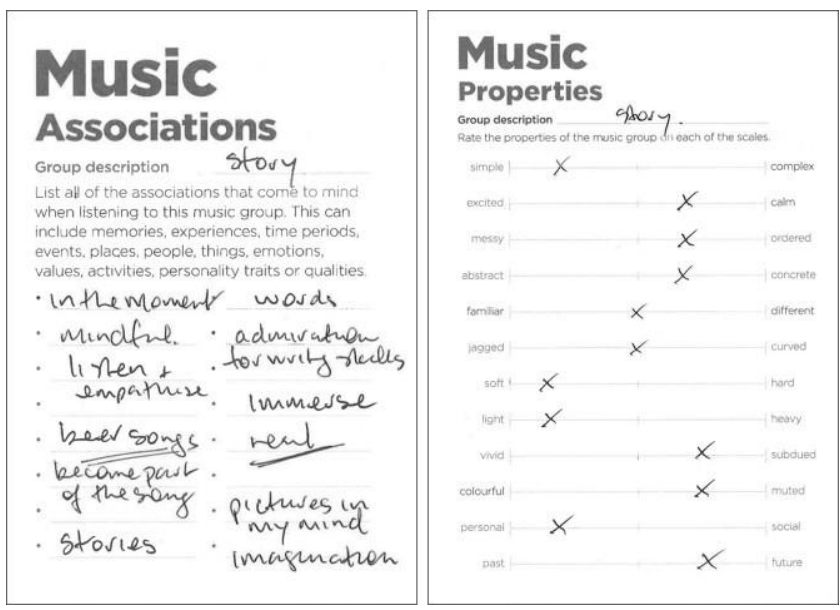

Figure 1. A Music Associations card (left) and a Music Properties card (right). 
music from within his digital library. Throughout the interview, Andrew played music from his digital library that further illustrated the thoughts and emotions that came to mind whilst listening to particular songs, artists, albums or genres.

\section{Interview 3: Materialising Musical Media}

The third interview, conducted three weeks later, was carried out in a café near Andrew's workplace and lasted 30 minutes. Prior to this interview, we transcribed and analysed data from the two prior interviews and probing activities to develop visual mood boards for each of the generated personal categories of music. We presented these mood boards to Andrew within the interview session to receive feedback on whether the imagery aligned with his perceptions of each music category. This was done to ensure our understanding of Andrew's relationship with his digital music library aligned with his own self-views. We also provided Andrew with an overview of the intended music player system and its components to openly discuss ideas for suitable imagery and interactions for each physical component.

\section{Phase 2: Creation}

We used the stories and insights shared by our participant as inspiration for the design of several embodiments of his music collection. We aimed to translate elements of the user's life narrative that are reflected by their digital music library to the physical design of a music player. This translation was intended to facilitate the formation of emotional value in the music player through its ability to characterise and communicate the significant memories, experiences and values evoked by the user's digital music.

To inform our design process, we conducted an analysis of the three interview sessions and probing activity responses. Each interview was transcribed with excerpt data coded for its links to aspects of Andrew's sense of self or music from within his digital library. This process provided inspirational data in the form of coded interview excerpts, listed associations, property ratings and evaluated mood board imagery that provide an overview of each category of music. Design concepts for the music player artefacts were judged by the authors for the significance, clarity, relevance and quantity of personal associations that they aim to embody. All components of the music player were created by the first author, an industrial designer with several years of industry experience. The ideation process was conducted in a similar manner to traditional design practice with a range of sketched concepts and paper prototypes explored prior to the creation of the final media embodiments and music player platform.

\section{Phase 3: Evaluation}

We concluded our process by evaluating the effectiveness of our designed music player system in developing meaningful associations that reflect the significance of the user's personal music library. Our participant Andrew was given the music player to incorporate within his day-to-day listening practices at home over a five-week period. At the conclusion of this period, we conducted a final interview to discuss his experiences with the music player. This involved the completion of an Object Associations card for each of the media embodiments used to control playback selection. Much like the Music Associations cards completed for each music category, Object Associations cards asked our participant to list all associations that came to mind when engaging with an artefact within the music player system. We also asked Andrew to compare the meaningfulness and authenticity of each object in embodying the personal significance ascribed to the digital music they contained. We concluded the interview by reflecting on Andrew's involvement throughout the research project. This evaluative interview was transcribed and analysed thematically [10] alongside reflections on the design process to determine the effectiveness of our approach in meaningfully integrating physical and digital components within a technological product.

\section{DESIGN PROCESS \& FINDINGS}

We present our findings within the three phases of the devised design process: inspiration, creation and evaluation.

\section{Phase I: Inspiration}

In this section, we provide a brief overview of Andrew's life narrative re-presented in the interview sessions, his relationship with music and the results of our probing activities, culminating in the development of four identitybased music categories extracted from his digital library.

\section{Andrew's Life Narrative}

Andrew is a 54-year-old father with a career in IT sales and client management. He grew up and continues to live near the northern beaches of Sydney. Throughout his life, Andrew has enjoyed staying active, being outdoors and attending local live music events. More recently, Andrew has picked up learning to play the bass. Some of his most cherished possessions include his collection of music posters from various live performances, his bass guitar and several books on rock music posters. In the near future, Andrew looks forward to retirement, freeing time for travelling and continuing to learn to play the bass. 


\section{Music Categories}

As part of our design process, we worked collaboratively with Andrew to develop a number of identity-based categories of music from within his digital music library. We used post-it notes to generate four distinct categories of music with which he has a rich relationship (see Figure 2 ). This was done to create divisions in the diversity of his digital music library in relation to the varying ways in which they relate to him personally. Music grouped under a particular category could relate to a particular artist, album or song from his library.

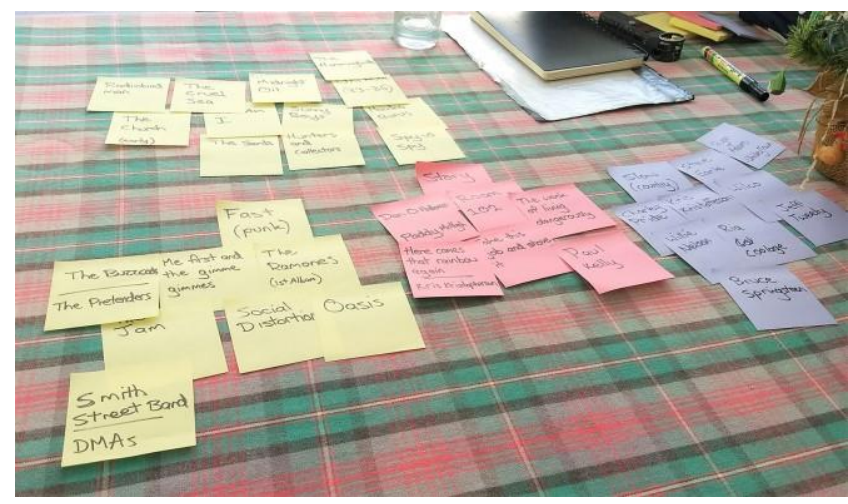

Figure 2. Developing identity-based music categories from Andrew's personal music library.

\section{Youth}

The first of the identity-based music categories was referred to simply as Youth, relating to music from Andrew's late teens and early 20's, coinciding with his time attending university. His appreciation for music grew rapidly during this period. Andrew credits this to his younger brother and friends playing in local bands and the vibrant local music scene across Sydney at the time. During this time, attending live music became a central part of Andrew's social life: "weekends got pretty much consumed by music". In addition to his social experiences, Andrew vividly recalls the abundance of artistic music posters wrapped around telegraph poles to advertise upcoming events that have become strongly associated to this category of music.

Music Associations: university, friends, fun, going out, growing up, getting drunk, [local venues], being young, fast, energy, lively, being 'alive', youth

Music Properties: simple, excited, messy, familiar, hard, heavy, vivid, colourful, personal, past

Example Artists: Sunnyboys, Hoodoo Gurus, Midnight Oil
Story

The second of the identity-based music categories was referred to as Story, relating to songs within Andrew's music library that contain lyrics that tell vivid stories. In contrast to the previous Youth category of music that contains personal associations to a specific time period, Andrew's relationship with music within the Story category is much more experiential. These songs create a uniquely immersive and vivid experience for Andrew as a listener: "I've just listened to a two-minute song and it's like I've watched a movie". We listened to many of the songs reported by Andrew to further aid our process of translating these immersive narrative experiences into material and visual qualities.

Music Associations: in the moment, mindful, listen \& empathise, beer songs, become part of the song, stories, words, admiration for writing skills, immerse, real, pictures in my mind, imagination

Music Properties: simple, calm, ordered, concrete, soft, light, subdued, muted, personal, future

Example Artists: Paul Kelly, Jason Isbell, Steve Earle

Slow

The third personally significant category of music from Andrew's digital music library, referred to as Slow relates to simple acoustic songs. Throughout Andrew's childhood, his family would take long road trips to visit relatives. During these road trips, his father would play country music through the car's speakers. While he had little interest in this music at the time, Andrew has since developed an appreciation for many of these songs. While listening to this music many years later, Andrew associates its simplicity to his younger self and the slower country lifestyle adopted on family trips away from the city. In reviewing our mood board for this music, Andrew emphasised a focus on imagery relating to the country musician rather than rural landscape.

Music Associations: being a kid, real stories, simple music, mum \& dad, relaxing, introspective, Fiat, road trips, wilderness, getting away from day-to-day, romantic, real, from the heart, Nashville

Music Properties: simple, calm, ordered, concrete, familiar, curved, soft, light, subdued, muted, personal, past

Example Artists: Charley Pride, Dolly Parton, Kris Kristofferson 
Fast

The final category of music highlighted in our collaborative design process was referred to as Fast, relating to the brash style of punk music from Andrew's library. Much like the Story category of songs, this music is predominantly valued experientially as refreshingly one-dimensional. Andrew described this category of music in relation to his experiences while growing up, discovering many of his favourite punk-rock bands in the transition to adulthood. Andrew's feedback to our mood board emphasised the attitude intrinsic to the Fast category of music: "it's just not serious, it's short, it's disposable, it's loud, it's funny..."

Music Associations: energetic, fast, aggressive, loud, brash, show-off, growing up, simple

Music Properties: simple, excited, messy, concrete, familiar, jagged, hard, heavy, vivid, colourful, present

Example Artists: Ramones, The Buzzcocks, The Jam

\section{Phase 2: Creation}

This section details the inspiration and design decisions that culminated in the creation of Melo, a bespoke music player containing four artefacts that collectively embody the personal significance of our participant's relationship with his music library (see Figure 3 ).

\section{Melo: A Bespoke Music Player}

Our design process resulted in the construction of a bespoke music player designed to possess meaningful materiality that integrates with the personal significance of the music it plays. It consists of a central platform and four unique objects that were inspired by Andrew's relationship with music from within his digital library. By placing one of the objects onto the central platform, Melo will begin to play songs from the correlated music category in random order. If the object sitting on the central platform is

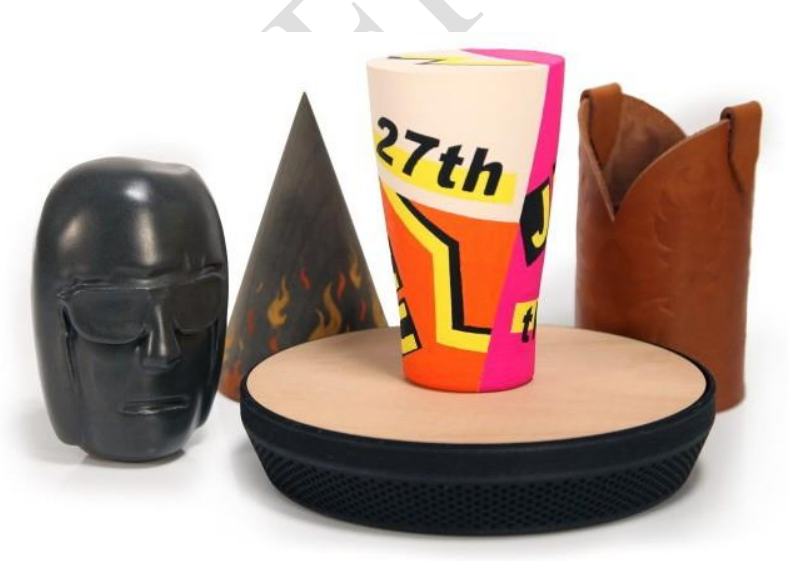

Figure 3. Melo: A bespoke music player. swapped with a different one, it will then play songs from the new object's music category. To stop playing songs, the object can be tapped onto the central platform a second time.

\section{Plast: An Object Embodying Andrew's Youth Music}

Andrew's personal associations to the Youth category of music were predominantly based on memories from his late teens and early 20's. His vivid descriptions of the graphic music posters frequently seen throughout his youth led us to explore ways to recreate their vibrant features and distinctive style. This process resulted in Plast (see Figure 4a), a hand-crafted object made from casted plaster and finished with gouache paints. We drewinspiration for the painted finish from an analysis of our probing activities, mood board feedback and examining a range of music posters from the early 1980's that reflected Andrew's descriptions. The design uses segmented block colours and bold, stencil text that depicts typical event details such as the performance date. All details were hand-painted, creating an imperfect brushstroke texture that echoes the unrefined style of posters. Gouache paint was chosen for its vibrant, matte finish.

\section{Ember: An Object Embodying Andrew's Story Music}

Andrew's Story category contains music with lyrics that create immersive narratives. Listening to these songs brought to mind vivid imagery for Andrew of "like-minded people sitting down and sharing stories". In response to our mood board, Andrew was drawn to images of wooden bar interiors, acoustic guitars and a warming fire. In our process, we sought ways of using the imagery of a campfire to bring about links between the physical object and the listening experience, resulting in Ember (see Figure 4b). We hand-turned a wooden cone to soften and condense the imagery of a campfire into a single form. Imagery of flames and smoke were added to the surface of the cone using a colour-wash technique, allowing the natural grain of the wood to remain visible.

\section{Hide: An Object Embodying Andrew's Slow Music}

Andrew's rich childhood recollections of long family road trips with his father's country music playing through the car speakers led us to explore imagery of simple details of rural landscapes with an emphasis on rich textures and colours. Andrew's collection of Slow music was found to evoke imagery of the country musician and rural lifestyle. This imagery was used in the design process of Hide (see Figure 4c), an object made from vegetable-tanned leather with imprinted patterns. In the design process of Hide, we drew upon imagery of iconic western leather cowboy boots, including pull tabs, raised sides and ornate patterns. We 
a.

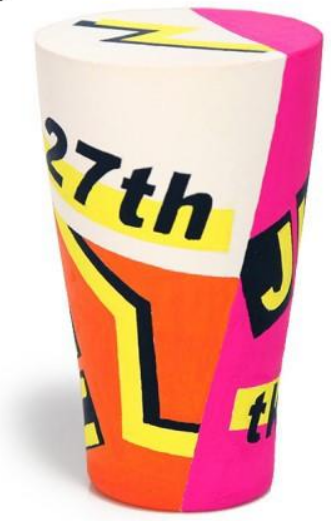

b.

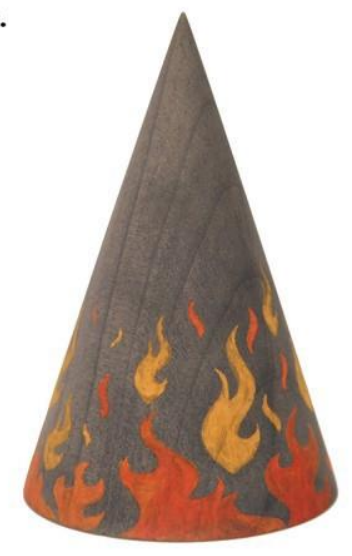

c.

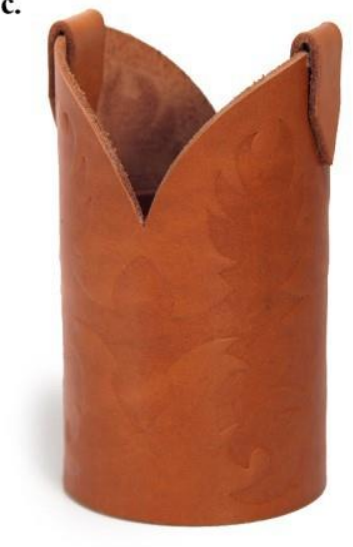

d.

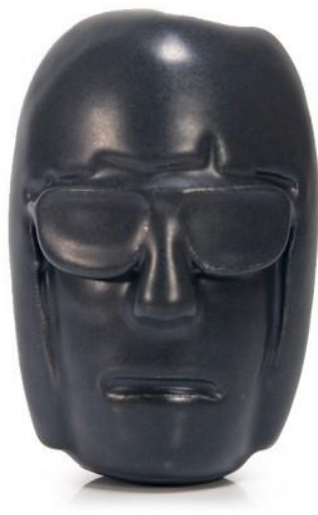

Figure 4. Playback Objects: Plast (a), Ember (b), Hide (c) and Joey (d).

opted to create a single, cylindrical form to reflect Andrew's appreciation for the simplicity of the music. Imprint details were used to provide subtle tactility to the object whilst being handled.

\section{Joey: An Object Embodying Andrew's Fast Music}

Andrew's punk-rock centric Fast category of music reflected an ongoing part of his identity that spans back to his formative years of early adulthood and was likened to "the image ofapunksortofcharacter". This input wasused to inspire our process of creating Joey, a character-like object made from porcelain and finished with a matte black glaze (see Figure 4d). We drew upon the appearances of musicians featured in the Fast category of music to create a character-like porcelain sculpture. Certain facial features adopted a simplified cartoon-type styling to emphasise the playful, tongue-in-cheek nature of the depicted character. A matte black glaze was used to echo the smooth texture of the black leather jackets worn by the featured musicians.

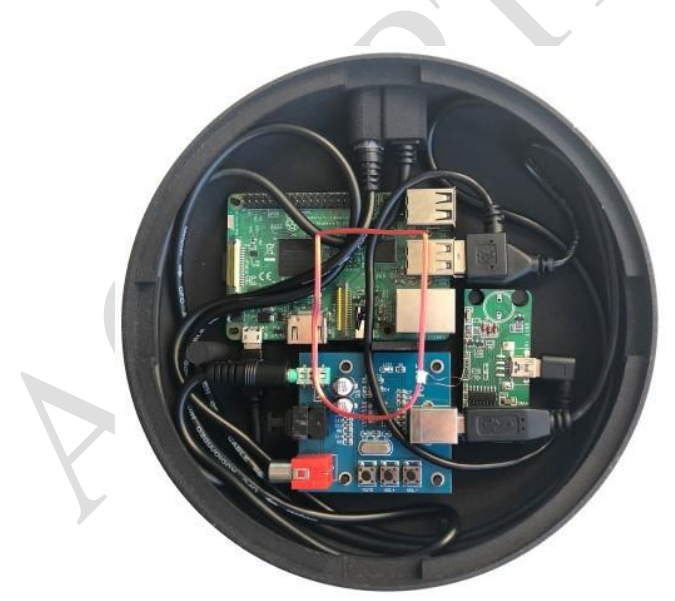

Figure 5. Technical components of Melo: A Raspberry Pi3, RFID reader and sound card.
Technical Details of Melo

The central platform was constructed from a 3D printed nylon base and laser cut blue gum veneer lid. This housed a Raspberry Pi 3 computer connected to a HiFi sound card and RFID card reader (see Figure 5). Unique RFID tags were attached to the base of each of the four objects. The Raspberry Pi 3 computer powered the software written in Python to detect when a RFID tag was placed in close proximity to the RFID card reader and to either play or stop playing songs from a specific digital music folder correlating to each of the unique tags. An external USB cable and $3.5 \mathrm{~mm}$ auxiliary audio cable were used to power the device and connect to household speakers.

\section{Phase 3: Evaluation}

In this section, we discuss the results of our deployment of Melo with Andrew over a five-week period. During deployment, Melo was set up in Andrew's lounge room, connecting to his existing home theatre speakers from which he would ordinarily play music via his smartphone. Andrew opted to use Melo exclusively when listening to music at home throughout the deployment period. He would most often use Melo to unwind after returning home on a Friday or Saturday night, typically whilst sitting on the couch having something to eat or watching sport (muted) on television.

Andrew's experiences of using Melo to listen to his digital music were overall positive. The limited functionality of Melo, only allowing for selection between four categories of music rather than individual songs was highly valued, providing Andrew with a greater sense of appreciation throughout his listening experiences: "the player allowed me to [...] sit down and appreciate [the music] rather than judge it and change it". These interactive properties had a 
strong effect on Andrew's listening habits. Selection between the four categories of music and associated objects was heavily mood-driven with extended periods of listening often transitioning from one of the more upbeat categories to a more mellow category or vice versa. Rather than actively monitoring and selecting songs for playback, Andrew would freely listen to music from one of the objects for hours at a time before switching to another music category. This change to his listening habits helped Andrew "relax a bit more" during his time spent unwinding in the evenings. Andrew also appreciated the inherent element of surprise involved in the random selection of songs from within a certain music category. This element of surprise was further emphasised in the early stages of use during which the specific songs associated with each object were still being discovered. Andrew recalled several occasions in which Melo played a lesser-known song from his collection, leading him to slowly rediscover the song's title, artist or album by carefully listening to its intro, melody, riff, lyrics or chorus.

\section{Object Associations}

Each of the four objects used to control Melo were evaluated for the associations they brought to mind, their mental connection to the music they embodied and their proximity to Andrew's sense of self. These evaluations were primarily comparative between the four different playback objects.

Plast was perceived to contain a clear link with the music it embodied and enabled when placed on the central platform. It had "blindingly obvious" associations with the upbeat, lively music from Andrew's youth. The form of Plast was associated with beer from our intended reference to the live music events hosted in local pubs and bars that Andrew fondly recalled. Andrew did not form associations relating to his appreciation for the graphic music posters that advertised these events, instead seeing parallels in the colours to the visual style of pop art. Ember was the least effective of the four objects in providing a clear association to the music it embodied. Throughout the deployment period, Andrew did not form a clear connection between Ember and the Story songs it would play, leading it to be perceived as mysterious. By the end of the deployment period, Andrew began to associate Ember with "stories around the fire" however it did not elicit the experiential associations of the immersive music itself. Andrew perceived Hide to contain the most obvious association to the music it embodied. The use of leather elicited strong country and western associations that plainly reflected the Slow music category. Joey was initially likened to a tiki mug (a sculptural ceramic mug). Much like Ember, this raised uncertainty for Andrew when using Joey to select music for playback. Over time and through closer inspection of the object, Andrew came to closely associate Joey with a member of the American punk-rock band, Ramones.

There were clear differences in Andrew's perception of each object relative to its proximity to his own sense of self. Both Plast and Joey were strongly associated with Andrew's self-identity, while Ember and Hide were less effective in doing so. This appraisal did not relate to the clarity of association between the object imagery and the personal category of music it embodied, but rather the materiality of the object in and of itself. The pop art feel of Plast and cartoony, bubblegum punk styling of Joey both reflected visual styles that Andrew closely identified with. In contrast to this, Andrew did not personally identify with the materials and imagery used in Hide and Ember, respectively.

In several instances, we were successful in creating intentional associations between an object and imagery related to the personal memories and experiences evoked by Andrew's music collection. While it is clear that our design decisions influenced the associations evoked by each of the four objects, we are reluctant to make overt claims that these decisions brought greater personal significance to the device itself. Each of the objects served functional purposes as a means of controlling the playback of Andrew's meaningful music collection. These interactions facilitate the process of forming factual connections between the objects and the music, irrespective of their material properties. Regardless, the specific associations evoked by our objects suggest that material design decisions made by designers are able to enrich ties between the physical and digital properties of technological products.

\section{Object Meaningfulness}

In our evaluation of the meaning assigned to each of the physical objects involved in the design of Melo, we found the associations ascribed to the device to stem from not only the digital music we aimed to embody, but also our user's pre-constructed understandings of product properties such as form, colour, texture, size and weight. Andrew's strong connection to the pop-art styling adopted in Plast and character-like styling adopted in Joey emphasised their relevance to his own sense of self. In contrast to this, the leather finish of Hide distanced the object from Andrew's sense of self and diminished its meaning, despite its strong association to the personally significant Slow music category. This reflects the need for a broader consideration of the ways in which people respond to and associate with the complex combination of 
properties involved in the materiality of the products they own.

The material forms of popular technological devices such as phones, tablets and digital cameras are often universal, devoid of qualities that reflect the diversity or specificity of the digital experiences they enable. It is often difficult to define and segregate personas and identity roles through the use and ownership of possessions in digital contexts [6]. Technological products may more effectively acquire associative meaning by specialising or demarcating their material and functional qualities to the practices conducted in a particular identity role. In the construction of our bespoke music player, we divided the digital music library into distinct categories, each with separate corresponding objects that relate to various aspects of the user's identity. While Melo is a single product, we believed it was essential to create multiple objects to reflect the diversity and depth of the significance of Andrew's relationship with his digital music library. There was a need for us to balance the specificity and universality of the device's materiality to reflect the divergent and shared qualities of the digital contents. Existing processes of managing digital media often store meaningful and meaningless items together, muddling their value [68]. Establishing systems that allow for greater distinctions between conceptually unified collections stored within physical devices may enable digital collections to more effectively enable self-extension processes.

Beyond our focus on materiality, the limited control that Melo provided over the selection of songs for playback was seen to contribute to its significance by providing a sense of anticipation: "[it was] not knowing what was going to happen but knowing that I would enjoy it when it did." Andrew likened using Melo to the experience of going to a band's live show: "you've got no control over what they're going to play and in what order [...] it was nice committing to that and then enjoying the experience." This suggests that physical and digital meanings may also be further integrated by designing physical interactions that enrich the experiential qualities of a user's engagements with their digital media.

\section{DISCUSSION}

We set out to explore ways in which design can support the development of meaningful ties between users and the materiality of technological devices. In doing so, we entered a dialogue with our participant in which they provided inspiration for and responses to a bespoke music player intended to reflect the personal significance associated with their personal library of digital music. Andrew's experience while engaging with our research product, Melo highlights the various ways in which people evaluate objects through their inferred associations.

\section{Opportunities and Considerations in Designing Meaningful Materiality}

Our process of associating the materiality of a technological device with its digital contents contains several promising aspects for promoting product attachment in the technological sector. Firstly, by creating associations to an ever-changing collection of personal digital media rather than a static source of meaning such as a memorable past experience. In this way, the materiality of the product is able to remain relevant to the user's present sense of self as the digital collection itself changes over time with the addition or removal of media. This allows for long-lasting attachment to develop, addressing sustainability concerns such as the rate of product consumption [32], a primary objective for many of the studies exploring this area of design $[14,28,48,49]$. Secondly, by utilising meaningful memories and associations within the design process as a method of promoting strong emotional bonds between users and products. Memories and associations are often argued to provide greater degrees of attachment than other identified determinants of product attachment $[45,54,56]$ and serve as a source of personal significance that is not easily replaced, improving the longevity of the product lifetime [43].

Designing for product attachment within the growing sector of technological products poses a unique issue in which the meaning assigned to a product may not be tied to the object itself but rather its digital functionality or contents [41, 64]. This issue remains largely unaddressed in the design strategies proposed in past studies of attachment to physical objects. Our focus on integrating the physical and digital components of a technological product increases the likelihood that the personal meaning assigned to a product is tied to its materiality, a key distinction for strategies intending to reduce the rate of product consumption $[43,53]$. Issues with our current rates of product consumption primarily stem from problems in our throwaway culture rather than the durability of the products themselves $[13,16,32,49]$. Designing technological devices to embody sources of personal significance aims to directly address this culture issue by ridding people of the desire to replace their belongings, even when a demonstrably superior product is obtainable.

While our process was effective in many ways, there are also several limitations to its application in design practice. 
Table 1. Overview of our preliminary process for embodying meaningful digital media.

\begin{tabular}{llll} 
Phase & Description & Example Methods \\
\hline $\begin{array}{l}\text { Meaningful } \\
\text { Media }\end{array}$ & $\begin{array}{l}\text { Identify a digital collection that is meaningful for the intended user. The digital } \\
\text { collection should contain ties to the intended user's life narrative or sense of } \\
\text { self. }\end{array}$ & $\begin{array}{l}\text { Interviews, narrative } \\
\text { inquiry, probe methodology }\end{array}$ \\
\hline 2 & $\begin{array}{l}\text { Media } \\
\text { Associations } \\
\text { and Imagery }\end{array}$ & $\begin{array}{l}\text { Identify the associations and imagery brought to mind by the meaningful } \\
\text { media, including emotions, values, personality traits, memories, experiences, } \\
\text { people, places, time periods and aesthetic or sensory properties. }\end{array}$ & $\begin{array}{l}\text { Interviews, probe } \\
\text { methodology, visualisation } \\
\text { methods (e.g. mood boards) }\end{array}$ \\
\hline 3 & $\begin{array}{l}\text { Material } \\
\text { Properties }\end{array}$ & $\begin{array}{l}\text { Identify the intended user's general views towards various material properties } \\
\text { such as colours, materials, textures and forms. }\end{array}$ & $\begin{array}{l}\text { Interviews, probe } \\
\text { methodology, } \\
\text { questionnaires }\end{array}$ \\
\hline 4 & $\begin{array}{l}\text { Synthesise } \\
\text { Properties }\end{array}$ & $\begin{array}{l}\text { Group together identified media associations or imagery and pre-constructed } \\
\text { views of material properties that share cohesive characteristics. }\end{array}$ & $\begin{array}{l}\text { Affinity mapping, thematic } \\
\text { analysis }\end{array}$ \\
\hline 5 & $\begin{array}{l}\text { Concept } \\
\text { Generation }\end{array}$ & $\begin{array}{l}\text { Generate design concepts from each of the synthesised properties, using the } \\
\text { identified associations, imagery and material properties as driving factors for } \\
\text { design decisions (e.g. selection of colour, texture, form, size and materials). }\end{array}$ & $\begin{array}{l}\text { Brainstorming, sketching, } \\
\text { model making }\end{array}$ \\
\hline
\end{tabular}

To elicit a desired associative response, designers are faced with the difficult task of anticipating another person's reaction to the products they create. Our music player was also designed for a single individual with inspiration derived from their unique life stories, an approach that is often not possible in traditional design practices. This limitation is partly inherent to the ways in which people form attachments to their belongings. Previous studies have highlighted that the experience of attachment is unique to the individual [45] and that it is not possible for one design to have emotional value for all intended users [22].

We see potential for utilising our process of materialising the meaningful associations ascribed to digital media in several emerging areas of practice, in particular the design of personal devices that contain curated or created media. Advancements in custom manufacturing technology such as additive manufacturing provide growing opportunities for bespoke material design practices such as those presented in this article as an alternative to traditional mass production processes. Similarly, technological advancements in the material forms of electronic components expand the possibilities of integrating digital information and interactions within traditionally nondigital forms.

\section{Embodying Meaningful Digital Media}

The material properties of the objects designed as part of Melo were an integral part of our attempt to materialise meaning. Our process of selecting materials, colours, forms, textures and imagery was heavily inspired by the interviews and probing activities conducted with our participant. While music is entirely immaterial, Andrew was able to clearly describe material and visual properties that came to mind in association with each of the four personal categories of music. We see this to reflect the remembering-imagining system presented by Conway and Loveday [15] that details how people use their imagination when remembering and use their memories when imagining. Andrew vividly associated his Fast music with imagery of a punk-type character, his Slow music with the outfits of western cowboys and his Story music with people sitting down and sharing stories, despite having no autobiographical memories of specific events in which this imagery was encountered. These depictions may best be described as imagined concepts that encompass the moods, emotions and feelings experienced while listening to the music. The ease of which Andrew was able to construct vivid imagery that encompassed each of his personal categories of music suggests that personal collections of digital media are able to be conceptualized in material terms, providing vast opportunities for designers to create closer connections between the physical world and the digital world.

Manipulating the material properties of a product in such a way as to elicit a desired associative response has long been used by designers as a strategy for influencing user perceptions [18]. Norman [46] illustrates how eliciting an associative response is used to improve the usability of products by using the example of door designs that provide signals to the user on whether they should be pushed or pulled to open. Our process instead aims to enable designers to use this approach to elicit an associative response that is personally meaningful for the user. We provide an overview of our process for developing meaningful material forms in Table 1. This process should 
not be seen as a prescriptive template for design practitioners, but instead as a source of inspiration for designers attempting to take steps towards promoting product attachment within their design processes. To summarise, our strategy involved identifying the personal meaning associated with a user's digital media and using this knowledge to design the physical device in such a way as to embody this meaning. This is intended to more deeply integrate physical and digital meanings of the device and requires careful consideration of the intended user's relationship with their digital media and the ways in which material properties may reinforce or enhance this relationship.

The bespoke nature of our process limits any claims of the generalisability of our findings and the effectiveness of our design strategy across broader contexts. This limitation is inherent to our adoption of research through design processes that instead decidedly remain future-oriented [69]. This future-oriented perspective shifts our focus from producing a design strategy that is generalisable to one that is extensible [70]. Our process and resulting artefact aim to serve as a specific instantiation of product attachment theory that begins to bridge current design practice toward our proposed, preferred state of human-object relationships. While by no means conclusive, our findings suggest there is merit in continuing to explore the value of embodying meaningful digital media as a means of promoting product attachment in the technological sector.

\section{CONCLUSION}

Despite their prevalence and significance in people's lives, technological devices are often perceived to be highly replaceable. From a sustainability perspective, there is value in creating technological products with meaning directly associated with their materiality to delay disposal and reduce the rate of resource consumption. We set out to explore the potential for design to promote the formation of product attachment by creating technological devices with meaningful materiality, closely integrating the physical form with the significance of its digital contents. We used the life stories and ongoing input of our intended user as inspiration for the creation of Melo, a bespoke music player. Our evaluation and critical reflection of our design process and resulting design highlight various factors for designers to consider in creating devices that hold meaning within their material forms. Designing the material and interactive properties of a device to embody the meaningful associations ascribed to digital media holds potential as a strategy for promoting product attachment within the growing sector of technological products. Embodying the meaning assigned to digital collections also provides an opportunity for extending and enriching their personal significance and role in identity formation processes. We intend for the process and resulting design presented in this article to inspire designers to further explore the value of materialising meaning in their practice to enrich userproduct relationships with both physical devices and collections of digital media.

\section{ACKNOWLEDGMENTS}

We would like to thank Andrew for his time and contributions. This study was approved by the UTS Ethics Committee (\#2015000629) and supported by STW VIDI grant number 016.128.303 of The Netherlands Organisation for Scientific Research (NWO), awarded to Elise van den Hoven and an Australian Government Research Training Program Scholarship awarded to Daniel Orth.

\section{REFERENCES}

[1] Aaron C Ahuvia. 2005. Beyond the extended self: Loved objects and consumers' identity narratives. Journal of consumer research 32,1 , 171-184.

[2] Ozgun Atasoy and Carey K Morewedge. 2017. Digital goods are valued less than physical goods. Journal of consumer research 44, 6 , 1343-1357.

[3] Peter Christopher Bach, Natalia Vyrva and Susanne Koch Stigberg. 2015. Tangible music player: Music collaboration. In Proceedings of the International Conference on Collaboration Technologies and Systems. IEEE, 399-406.

[4] A Dwayne Ball and Lori H Tasaki. 1992. The role and measurement of attachment in consumer behavior. Journal of Consumer Psychology $1,2,155-172$

[5] Russell W Belk. 1988. Possessions and the extended self. Journal of consumer research 15, 2, 139-168.

[6] Russell W Belk. 2013. Extended self in a digital world. Journal of consumer research 40, 3, 477-500.

[7] Russell W Belk. 2014. You are what you can access: Sharing and collaborative consumption online. Journal of business research 67,8 , 1595-1600.

[8] Albert Borgmann. 1984. Technology and the character of contemporary life: A philosophical inquiry. University of Chicago Press.

[9] John Bowlby. 1977. The making and breaking of affectional bonds: I. Aetiology and psychopathology in the light of attachment theory. The British Journal of Psychiatry 130, 3, 201-210.

[10] Virginia Braun and Victoria Clarke. 2006. Using thematic analysis in psychology. Qualitative research in psychology 3, 2, 77-101.

[11] Barry Brown and Abigail Sellen. 2006. Sharing and listening to music. In Consuming music together: Social and collaborative aspects of music consumption technologies, K. O'Hara and B. Brown (Eds.). Springer, The Netherlands, 37-56.

[12] J Allison Bryant and Anna Akerman. 2009. Finding mii: Virtual social identity and the young consumer. In Virtual social identity and consumer behavior, N. Wood and M. Solomon (Eds.). M. E. Sharpe, Armonk, NY, 127-140.

[13] Jonathan Chapman. 2008. Emotionally durable design: Sustaining relationships between users and domestic electronic products. University of Brighton.

[14] Jonathan Chapman. 2014. Meaningful stuff: Toward longer lasting products. In Materials experience: Fundamentals of materials and design, E. Karana, O. Pedgley, \& V. Rognoli (Eds.). ButterworthHeinemann, Oxford, UK, 135-143. 
[15] Martin A Conway and Catherine Loveday. 2015. Remembering, imagining, false memories \& personal meanings. Consciousness and cognition 33, 574-581.

[16] Tim Cooper. 2002. Durable consumption: Reflections on product life cycles and the throwaway society. In Proceedings of the Lifecycle Approaches to Sustainable Consumption Workshop,11-27.

[17] Carolyn L Costley. 1988. Meta analysis of involvement research. NA - Advances in Consumer Research 15, 554-562.

[18] Nathan Crilly, James Moultrie and P. John Clarkson. 2009. Shaping things: Intended consumer response and the other determinants of product form. Design Studies 30, 3, 224-254.

[19] Mihaly Csikszentmihalyi and Eugene Rochberg-Halton. 1981. The meaning of things: Domestic symbols and the self. Cambridge University Press.

[20] Wen-Jing Deng, John P Giesy, Cs So and Hai-Long Zheng. 2017. Endof-life (eol) mobile phone management in hong kong households. Journal of Environmental Management 200, 22-28.

[21] Tia Denora. 1999. Music as a technology of the self. Poetics 27, 1, $31-$ 56.

[22] Pieter Desmet, Kees Overbeeke and Stefan Tax. 2001. Designing products with added emotional value: Development and application of an approach for research through design. The Design Journal 4, 1, 32-47.

[23] Melanie Feinberg. 2013. Beyond digital and physical objects: The intellectual work as a concept of interest for hci. In Proceedings of the SIGCHI Conference on Human Factors in Computing Systems. ACM, 3317-3326.

[24] George W Fitzmaurice. 1996. Graspable user interfaces. University of Toronto.

[25] Susan Fournier. 1998. Consumers and their brands: Developing relationship theory in consumer research. Journal of consumer research 24, 4, 343-373.

[26] Christopher Frayling. 1993. Research in art and design. Royal College of Art Research Papers 1, 1, 1-5.

[27] Daniel Gallardo and Sergi Jordà. 2010. Tangible jukebox: Back to palpable music. In Proceedings of the Fourth International Conference on Tangible, Embedded, and Embodied Interaction. ACM, 199-202.

[28] Silke Gegenbauer and Elaine M Huang. 2012. Inspiring the design of longer-lived electronics through an understanding of personal attachment. In Proceedings of the Conference on Designing Interactive Systems. ACM, 635-644.

[29] Connie Golsteijn, Elise Van Den Hoven, David Frohlich and Abigail Sellen. 2012. Towards a more cherishable digital object. In Proceedings of the Conference on Designing Interactive Systems. ACM, 655-664.

[30] Connie Golsteijn, Elise Van Den Hoven, David Frohlich and Abigail Sellen. 2014. Hybrid crafting: Towards an integrated practice of crafting with physical and digital components. Personal and Ubiquitous Computing 18, 3, 593-611.

[31] David Hesmondhalgh. 2008. Towards a critical understanding of music, emotion and self-identity. Consumption, Markets and Culture $11,4,329-343$.

[32] Elaine M Huang and Khai N Truong. 2008. Breaking the disposable technology paradigm: Opportunities for sustainable interaction design for mobile phones. In Proceedings of the SIGCHI Conference on Human Factors in Computing Systems. ACM, 323-332.

[33] Hiroshi Ishii and Brygg Ullmer. 1997. Tangible bits: Towards seamless interfaces between people, bits and atoms. In Proceedings of the SIGCHI Conference on Human Factors in Computing Systems. ACM, 234-241.

[34] David S Kirk and Abigail Sellen. 2010. On human remains: Values and practice in the home archiving of cherished objects. ACM Transactions on Computer-Human Interaction 17, 3,10.

[35] Moon-Hwan Lee, Oosung Son and Tek-Jin Nam. 2016. Patinainspired personalization: Personalizing products with traces of daily use. In Proceedings of the Conference on Designing Interactive Systems. ACM, 251-263.

[36] Charlotte Linde. 1993. Life stories: The creation of coherence. Oxford University Press.
[37] Paolo Magaudda. 2011. When materiality 'bites back': Digital music consumption practices in the age of dematerialization. Journal of Consumer Culture 11, 1, 15-36.

[38] Rebecca Mardon and Russell Belk. 2018. Materializing digital collecting: An extended view of digital materiality. Marketing Theory $18,4,543-570$.

[39] Jennifer Martin. 2008. Consuming code: Use-value, exchange-value, and the role of virtual goods in second life. Journal of Virtual Worlds Research 1,2, 21 .

[40] Tom Mccourt. 2005. Collecting music in the digital realm. Popular Music and Society 28, 2, 249-252.

[41] Alexander Meschtscherjakov, David Wilfinger and Manfred Tscheligi. 2014. Mobile attachment causes and consequences for emotional bonding with mobile phones. In Proceedings of the SIGCHI Conference on Human Factors in Computing Systems. ACM, 2317 2326.

[42] Elena Mugellini, Elisa Rubegni, Sandro Gerardi and Omar Abou Khaled. 2007. Using personal objects as tangible interfaces for memory recollection and sharing. In Proceedings of the First International Conference on Tangible and Embedded Interaction. ACM, 231-238.

[43] Ruth Mugge, Jan Pl Schoormans and Hendrik Nj Schifferstein. 2005. Design strategies to postpone consumers' product replacement: The value of a strong person-product relationship. The Design Journal 8, $2,38-48$.

[44] Elizabeth Myers. 1985. Phenomenological analysis of the importance of special possessions: An exploratory study. NA - Advances in Consumer Research 12, 560-565.

[45] Kirsi Niinimäki and Ilpo Koskinen. 2011. I love this dress, it makes me feel beautiful! Empathic knowledge in sustainable design. The Design Journal 14, 2, 165-186.

[46] Donald A Norman. 1988. The design of everyday things. Basic Books, New York.

[47] Michael Nunes, Saul Greenberg and Carman Neustaedter. 2008. Sharing digital photographs in the home through physical mementos, souvenirs, and keepsakes. In Proceedings of the Conference on Designing Interactive Systems. ACM, 250-260.

[48] William Odom and James Pierce. 2009. Improving with age: Designing enduring interactive products. In Proceedings of the SIGCHI Conference on Human Factors in Computing Systems. ACM, 3793-3798.

[49] William Odom, James Pierce, Erik Stolterman and Eli Blevis. 2009. Understanding why we preserve some things and discard others in the context of interaction design. In Proceedings of the SIGCHI Conference on Human Factors in Computing Systems. ACM, 10531062.

[50] William Odom, John Zimmerman and Jodi Forlizzi. 2011. Teenagers and their virtual possessions: Design opportunities and issues. In Proceedings of the SIGCHI Conference on Human Factors in Computing Systems. ACM, 1491-1500.

[51] William Odom, John Zimmerman and Jodi Forlizzi. 2014 Placelessness, spacelessness, and formlessness: Experiential qualities of virtual possessions. In Proceedings of the Conference on Designing Interactive Systems. ACM, 985-994.

[52] Daniel Orth, Clementine Thurgood and Elise Van Den Hoven. 2018. Designing objects with meaningful associations. International Journal of Design 12, 2, 91-104.

[53] Daniel Orth, Clementine Thurgood and Elise Van Den Hoven. 2019. Designing meaningful products in the digital age: How users value their technological possessions. ACM Transactions on ComputerHuman Interaction 26, 5, 34

[54] Tom Page. 2014. Product attachment and replacement: Implications for sustainable design. International Journal of Sustainable Design 2, $3,265-282$.

[55] Daniela Petrelli and Steve Whittaker. 2010. Family memories in the home: Contrasting physical and digital mementos. Personal and Ubiquitous Computing 14, 2, 153-169.

[56] Hendrik Nj Schifferstein and Elly Ph Zwartkruis-Pelgrim. 2008. Consumer-product attachment: Measurement and design implications. International Journal of Design 2, 3, 1-13. 
[57] Susan E Schultz, Robert E Kleine and Jerome B Kernan. 1989. "These are a few of my favorite things": Toward an explication of attachment as a consumer behavior construct.Advances in Consumer Research 16, 1, 359-366.

[58] Shakeel Siddiqui and Darach Turley. 2006. Extending the self in a virtual world. NA - Advances in Consumer Research 33, 647-648.

[59] Maria Ek Styvén. 2010. The need to touch: Exploring the link between music involvement and tangibility preference. Journal of business research 63, 9-10, 1088-1094.

[60] Phil Turner and Susan Turner. 2013. Emotional and aesthetic attachment to digital artefacts. Cognition, technology \& work 15, 4, 403-414.

[61] Anna Vallgårda and Johan Redström. 2007. Computational composites. In Proceedings of the SIGCHI Conference on Human Factors in Computing Systems. ACM, 513-522.

[62] Elise Van Den Hoven and Berry Eggen. 2004. Tangible computing in everyday life: Extending current frameworks for tangible user interfaces with personal objects. In Proceedings of the European Symposium on Ambient Intelligence. Springer, 230-242.

[63] Peter-Paul Verbeek. 2005. What things do: Philosophical reflections on technology, agency, and design. Penn State Press.
[64] Jane Vincent. 2006. Emotional attachment and mobile phones. Knowledge, Technology \& Policy 19, 1, 39-44.

[65] Amy Voida, Rebecca E Grinter, Nicolas Ducheneaut, W Keith Edwards and Mark W Newman. 2005. Listening in: Practices surrounding itunes music sharing. In Proceedings of the SIGCHI Conference on Human Factors in Computing Systems. ACM, 191-200.

[66] Rebecca Watkins and Mike Molesworth. 2012. Attachment to digita virtual possessions in videogames. In Research in Consumer Behavior. S. Askegaard, R. W. Belk, and L. Scott (Eds.). Emerald Group Publishing Limited, Bingley, UK, 153-170.

[67] David West, Aaron Quigley and Judy Kay. 2007. Memento: A digitalphysical scrapbook for memory sharing. Personal and Ubiquitous Computing 11, 4, 313-328.

[68] Steve Whittaker. 2011. Personal information management: From information consumption to curation. Annual Review of Information Science and Technology 45, 1, 1-62.

[69] John Zimmerman and Jodi Forlizzi. 2008. The role of design artifacts in design theory construction. Artifact 2, 1, 41-45.

[70] John Zimmerman, Jodi Forlizzi and Shelley Evenson. 2007. Research through design as a method for interaction design research in hci. In Proceedings of the SIGCHI Conference on Human Factors in Computing Systems. ACM, 493-502. 